peas are then replaced in the dark box for twentyfour hours, after which they are removed and the cut height (2) is measured by the millimetre rule and the millimetre scale. The maximum and minimum temperature during the experiment are recorded.

More than two hundred tests have been carried out using hypocotyls and epicotyls of different species of seedlings, examples of which are shown in Table $\mathrm{I}$. Control experiments were made by using portions from the base of hypocotyls where growth was known to have ceased and others with lanoline alone applied to the pea stumps. Definite increase in the height of the pea stumps was shown by the application of the actively growing plant material and this could be measured correctly to $0.5 \mathrm{~mm}$. This increased growth is attributable to the amount of growth substance which diffuses out from the plant material applied on the lanoline which restimulates growth in the pea stump.

In order to attempt some standardization of this induced growth, experiments were performed with indole-3-acetic acid in one per cent solution $(0.1 \mathrm{mgm}$. acid per litre). This was first applied in lanoline, a paste being made by mixing 0.25 c.c. with $0.5 \mathrm{gm}$. of lanoline. Results from this experiment were variable owing to the difficulty of obtaining an even mixture and equal applications to each pea. More experiments were made with the indole-3-acetic acid mixed with a 3 per cent agar gel. Mixtures of equal parts acid and melted agar and one part acid to two parts agar were made into blocks which were applied to the pea stumps. The blocks were made by sucking up the agar mixture into a straw, in which it cooled and set. Then blocks of the required length can be cut with a razor blade and in applying them to the pea stump the straw acts as a support for the agar block. The blocks used were $5 \mathrm{~mm}$. long and approximately 40 c.mm. in volume, which is much larger than those used for the Avena test but of approximately the same volume as the segments of Lupinus albus hypocotyls, with which many of the experiments were performed, and a convenient size to fit on to the pea stumps. The blocks were placed on the pea on lanoline as described above.

Results recorded in Table 2 show that a block of 40 c.mm. containing 1: 2 parts indole-3-acetic acid in 3 per cent agar would produce an increase of $1 \mathrm{~mm}$. in the pea stump. Blocks made of 1:1 acid and agar produce greater increase but more variable results. It is, therefore, suggested that an increase of $1 \mathrm{~mm}$. in the pea stump should be regarded as a standard for measurement of the amount of growth substance which has diffused out of the test material, one 'pea unit' being that amount of growth substance which diffuses from an applied block of plant material causing an increase of $1 \mathrm{~mm}$. in height of the pea stump and is equivalent to the growth caused by a block of $1: 2$ indole-3-acetic acid $(0.1 \mathrm{mgm}$. per litre) in 3 per cent agar at a temperature $72-54^{\circ} \mathrm{F}$. and 100 per cent relative humidity.

According to Went $^{1} 0.5$ per cent indole-3-acetic acid solution in a $10 \mathrm{c} . \mathrm{mm}$. agar block, at $24^{\circ} \mathrm{C}$, and 85 per cent relative humidity would produce $5^{\circ}$ curvature in the Avena test, so that the results for the pea method show that an increase of $1.0 \mathrm{~mm}$. in the pea stump would approximate to $5^{\circ}$ curvature in the pea test.

1 Went, F. and W., and Thimann, K. V., "Phytohormones", p. 41
(New York: The Macmillan Company, 1937.)

\title{
SCIENTIFIC AND INDUSTRIAL RESEARCH IN NEW ZEALAND
}

\begin{abstract}
$\mathrm{T}$ HE fifteenth annual report of the Department of Scientific and Industrial Research, New Zealand, covers the year 1940-41 and includes the Minister's statement, the report of the Secretary, together with reports of the research committees of the Council of Scientific and Industrial Research and of the work of the Plant Research Bureau, Wheat Research Institute, Magnetic Observatory, Dominion Laboratory Geological Survey Branch, and Metrological Branch*.

The Dairy Research Institute has been occupied with urgent problems relating to the storage and transport of dairy produce under war conditions, and particularly with the view of prolonging the keeping quality of dairy produce likely to be in storage for long periods and methods of packaging and processing butter and cheese to conserve shipping space and weight and packing materials. Special starter rooms embodying the Institute's recommendations for preserving the vitality of starters were erected by some fifteen dairy factories during the past season.

The work of the Plant Research Bureau during the year has been concentrated on minimizing losses in pasture, arable and horticultural crops by intensifying control measures, the maintenance of full supplies of certified pasture and crop seeds and the

- New Zealand. Fifteenth Annual Report of the Department of Scientiflc and Industrial Research. Pp. 92. (Wellington Government Printer, 1941.) $9 d$.
\end{abstract}

propagation and collection of important medicina plants to help supply emergency requirements in Great Britain and locally. Attention has also been given to local substitutes for imported plant materials such as seaweed products like agar and carrageen, the most efficient methods of preparing and conserving supplementary fodders and the instructional and research work required by the administration of the Termites Act, 1940. A considerable amount of work has been carried out on linen flax. The Plant Diseases Division at Owairaka, Auckland, has tested a number of organic mercurials for control of Corticium vagum, and has examined a number of copper compounds against standard Bordeaux mixture and biological work on sulphur sprays and the testing of derris products. Spray investigations and demonstrations in the field of fruit research have also been continued by the Division, while other work has been directed to the study of the insects attacking timber in an endeavour to select those satisfactory for testing timber preservatives and timber treatments. Tobacco research has included further work on the investigation of mosaic and that at the Cawthron Institute on control of damping-off fungi with soil dressings gave promise of success. Use of Semesan and zinc oxide with seed did not give satisfactory results, although Semesan gave satisfactory control if mixed with the soil to a depth of $\frac{s}{2}$ in. The outstanding 
problems in fruit research have been concerned with methods of storing under the best possible conditions the surplus of fruit thrown on the local market when export stopped. This has involved resorting to orchard storage on a greatly increased scale to supplement cold storage facilities. Experimental work in co-operation with the Cawthron Institute has yielded valuable information regarding the optimum conditions of temperature and humidity in orchard stores, the best methods of wrapping and packing and the varieties and grades of fruit best suited for orchard storage.

Work at the Plant Chemistry Laboratory received a severe set-back through the destruction of the laboratory and a greater part of its equipment by fire during the year. Very good work has, however, been done under difficult conditions in supplying a considerable amount of alkaloidal material from perennial rye-grass to the Department of Agriculture for animal experiments in connexion with facial eczema studies and in obtaining chemical data on the digestibility or nutritive value of silage from selected pastures. Chemical studies on the effect of naphthylacetic acid on the composition of cuttings and on the relation of accessory substances such as auxines and vitamins to soil fertility has continued. In collaboration with the Mines Department surveys of minerals of strategic value and special economic importance in war-time have been intensified, including surveys of local resources of such minerals as serpentine, magnesite, oil shale, sulphur, sands and clays. A special committee was set up to co-ordinate investigations by the Department of Agriculture and Scientific Industrial Research, the Cawthron Institute and the Canterbury Agricultural College on the manufacture and agricultural value of a reverted phosphatic fertilizer obtained by incorporating ground serpentine with superphosphate.

The activities of the research associations servicing the tanners, the boot and shoe manufacturers and the wool manufacturers have been directed specially to war-time manufacturing problems, including the provision of satisfactory substitutes for imported materiels which are not now available. Other investigations have been concerned with local substitutes for imported pottery materials, adhesives, agar and carrageen. The Physical Testing Laboratory, in addition to a large amount of work on physical testing and precision-instrument constructing, is extending its operations in regard to standards of reference for use in connexion with the manufacture of munitions.

The Chemical Engineering Section of the Dominion. Laboratory has been largely occupied with the investigation of producer gas as an emergency fuel for motor vehicles, and its semi-commercial trials on the gas storage of apples to improve their keeping qualities for local consumption has yielded valuable data. Much chemical work has been done in connexion with a survey of national coal resources, and other work has been concerned with stone preservation and spray residues on cabbages, and investigations on casein paint and on the utilization of bentonite are also in progress.

The Geological Survey has carried out special geological and geophysical surveys for the Public Works Department in the Waikato in connexion with hydroelectric developments, and a re-survey of magnetic stations throughout New Zealand is being made to provide data required by the defence services.

\section{FORTHCOMING EVENTS \\ [Meeting marked with an asterisk is open to the public.]} SATURDAY, NOVEMBER 29

Broohamoal Socretr (at the Courtauld Institute of Biochemistry, Middlesex Hospital, London, W.1), at 11 a.m.-Dr. G. M. Findlay will open a general discussion on "The Mode of Action of Chemotherapeutic Agents".

Instinute of Physics (Manchestier AND Distriot Branoh) (in the Physics Department, The University, Manchester), at 2.30 p.m.Prof. M. L. Oliphant, F.R.S. : "Physics in the United States and Recent Practical Applications of Nuclear Physics"."

MONDAY, DECEMBER 1

ROYAL GrographicaI SOCIRTY (at Kensington Gore, London, S.W.7), at 3 p.m.-Capt. R. Hamond: "Through Western Tibet in 1939",

ROYAl Society of ARTs (at John Adam Street, Adelphi, London, W.C.2), at 1.45 p.m. Mr. A. J. Curtin Cosbie: "Brewing, the Story of a National Industry" -3 : "Brewing Research" (Cantor Lectures, III).

TUESDAY, DECEMBER 2

ROYAL INSTITUTHON OF GREAT BRITAIN (at 21 Albemarle Street, London, W.1), at 2.30 p.m.-Prof. J. C. Drummond : "Recent Advances in the Science of Nutrition and their Significance in War-

WEDNESDAY, DECEMBER 3

SOCTETY OF CHEMTCAL INDUSTRY (FOOD GROUP) (Joint Meeting with the Society of Public Anslysts) (at the Chemical Society, Burlington House, Piccadilly, London, W.1), at 11 a.m.-Mr. A. L. Bacharach : "The Nutritional Bases for Fortiflcation of Foods",

\section{THURSDAY, DECFMBER 4}

ROYAL INSTITUTION OF GReAT BRITAIN (at 21 Albemarle Street, London, W.1), at $2.30 \mathrm{p} . \mathrm{m}$-Prof. Benjamin Farrington: "The Hand in Healing : a Study in Greek Medicine from Hippocrates to Ramazzini".

FRIDAY，DECEMBER 5

Assoctation of APPLIED BIOLOGIsTs (at the London School of Hygiene and Tropical Medicine, Keppel Street, London, W.C.1), at 11 a.m.Discussion on "Some Problems in Wartime Horticulture with particular reference to Vegetable Production".

SATURDAY, DECEMBER 6

INSTITUTR of Physics (LONDON AND HOME COUNMIES' BRANOH) (at the South-West Essex Technical College, Forest Road, Walthamstow, London, E.17), at 2.30 p.m.-Dr. W. G. Wearmouth : "Physical Problems in the Plastics Industry".

\section{APPOINTMENTS VACANT}

APPLICATIONS are invited for the following appointments on or before the dates mentioned :

Skeior Lecturer (ungraded) in the Department of BiochemistryThe Registrar, The University, Liverpool (December 6). THACHRR of GLECTRIOAL ENGIN RERING AND ALIIED SubJrcrs in
the Cambridgeshire Technical School-The Education Secretary, Shire Hall, Cambridge (December 8 )

ENarwere for the Sierra Leone Public Works Department-The Ministry of Labour and National Service, Central Register Branch. Queen Anne's Cbambers, Tothill Street, Iondon, S.W.1 (quoting E. 338).

\section{REPORTS AND OTHER PUBLICATIONS}

(not included in the monthly Books Supplement) Great Britain and Ireland Philosophical Transactions of the Royal Society of London. Series
B : Biological Sciences. No. 578, Vol. 231: The Heart of the Salamander (Salamandra salamandra, L.), with Special Reference to the Conducting System and its Bearing on the Phylogeny of the Conducting Systems of Mammates and E. T. B. Francis. Pp. 99-130 +plates 7-8. (London: Cambridge
University Press.) 78. [411
The Amazing Insects. By G. E. O. Knight. Pp. 16. (London: Insecta-Mammalia.) 18.
[41]

Editorial and Publishing Offices
MACMILLAN \& CO., LTD.,
ST. MARTIN'S STREET, LONDON, W.C.2.
Telephone: Whitehall 883। Telegrams': Phusis Lesquare London
Advertisements should be addressed to
T. G. Scott \& Son, Ltd., Three Gabies, London Road, Merstham, Surrey
Telephone: Merstham 316
Telephone: Merstham 316

The annual subscription rate is $\$ 4100$, payable in advance, Inland or Abroad All rights reserved. Registered as a Newspaper at the General Post Office 